\title{
Hospital distribution in a metropolitan city: assessment by a geographical information system grid modelling approach
}

\author{
Kwang-Soo Lee ${ }^{1}$, Kyeong-Jun Moon ${ }^{2}$ \\ ${ }^{1}$ Department of Health Administration, College of Health Sciences, Yonsei University, Wonju, Gwangwondo, \\ South Korea; ${ }^{2}$ Department of Health Administration, Graduate School, Yonsei University, Wonju, Gwangwondo, \\ South Korea
}

\begin{abstract}
Grid models were used to assess urban hospital distribution in Seoul, the capital of South Korea. A geographical information system (GIS) based analytical model was developed and applied to assess the situation in a metropolitan area with a population exceeding 10 million. Secondary data for this analysis were obtained from multiple sources: the Korean Statistical Information Service, the Korean Hospital Association and the Statistical Geographical Information System. A grid of cells measuring $1 \times 1 \mathrm{~km}$ was superimposed on the city map and a set of variables related to population, economy, mobility and housing were identified and measured for each cell. Socio-demographic variables were included to reflect the characteristics of each area. Analytical models were then developed using GIS software with the number of hospitals as the dependent variable. Applying multiple linear regression and geographically weighted regression models, three factors (highway and major arterial road areas; number of subway entrances; and row house areas) were statistically significant in explaining the variance of hospital distribution for each cell. The overall results show that GIS is a useful tool for analysing and understanding location strategies. This approach appears a useful source of information for decision-makers concerned with the distribution of hospitals and other health care centres in a city.
\end{abstract}

Keywords: hospital, health care, geographical information system, grid method, strategy, location, South Korea.

\section{Introduction}

Geographical location is a key factor influencing the performance in the health care market. Jones et al. (1982) compared two hospital locations and found differences in emergency room (ER) use despite similarities with regard to patient population, while Wilson and Tedeschi (1984) analysed variation in patient-day rates among hospitals and discovered that the supply of medical care resources, e.g. emergency care beds, had a strong influence. Peled et al. (2006) applied a geographical information system (GIS) for allocating sites for quality assurance and disease management of asthma patients, and Messina et al. (2006) analysed the distribution of community hospital pattern evaluating the accessibility to hospitals. To further support the identification of under-served areas with respect to hospital services, Vahidnia et al. (2009) combined GIS analysis with a fuzzy analytical hierarchy process to determine

\footnotetext{
Corresponding author:

Kwang-Soo Lee

Department of Health Administration

School of Health Sciences, Yonsei University

1 Yonseidae-gil, Wonju, Gangwon-do 220-710, South Korea

Tel. +82 33-760-2426; Fax +82 33-760-2519

E-mail: planters@yonsei.ac.kr
}

suitable hospital sites in an urban area. Lee et al. (2007) analysed an association between geographical distance and ER utilization and found that distance had influences on the utilisation of ER services.

Overall, it can be argued that GIS can play an important role in the support of hospital planning and placement. However, it can also be used for the location of primary care centres; e.g. Wong et al. (2010) analysed the spatial distribution of methadone clinic clients finding that clinic location had a clear influence on the pattern of visits. Tanser (2006) showed that GIS could facilitate accessibility when applied for the planning of new primary health care facilities in rural areas, and Alcatraz et al. (2009) observed that some community settings are more likely to be used than others if its clinics are planned with the aim of reaching the local population, in particular cancer patients.

GIS is a spatial analytic tool that can store and manipulate multiple forms of data, which is a strong reason to identify it as a platform for analysing data related to the location of health care sites. It allows researchers to analyse data in map format at various levels of geographical detail (Murad, 2008; Passalent et al., 2013). GIS is therefore a powerful tool for the assessment and analysis of health data and it affords researchers the opportunity to visualise, explore and model health issues (Graves, 2008). GIS has been widely applied for 
analysing location issues in health services research (Walsh et al., 1997; Rosero-Bixby, 2004; Mitropoulos et al., 2006; Schuurman et al., 2008; Passalent et al., 2013) not only enabling access to information from traditional administrative boundaries, but also allowing the collection of data from areas defined by researchers.

To improve the performance of health care delivery, especially for hospitals, decision-makers need to show an interest in location. It is of importance to not only consider methodologies defining optimal running of hospitals, but also to look at the accessibility issue and other environmental factors. Apart from general ideas about allocating hospital resources, it would also be useful to assess location at the micro-level, as this would help formulating ways to analyse the demographic features of local people with increased need for health care, such as the elderly and those in poor health. This approach would bring the extra benefit of enabling hospital managers to select the types of medical departments appropriate for the need of the particular population categories.

Previous, spatial analyses of health care services have been criticised for using large areal units when analysing data that often failed to produce meaningful results. Love and Lindquist (1995) argued that using a ratio variable, such as the number of county hospital beds to county population, limited analytical sensitivity and failed to properly identify the relationship between the location of a health care centre and its immediate environment. They proposed that spatial analysis based on much smaller areas than the administrative one would provide more reliable information in evaluating the local environment. Kassaye and Tseng (1990) analysed the relationship between socio-demographic factors and the provision of hospital services at different levels. They found that hospitals more readily respond to alterations in the micro-environment than to large-scale changes in a macro-environment. This suggests that health-related decision-making such as defining the location of hospitals could be better if supplied with information generated by a geographical model operated at the micro-level. In accordance with these thoughts, rather than using traditional administrative boundaries as the geographical unit of analysis, this study applied a grid method dividing the study area into small units of identical size suitable for multivariate regression analysis, an approach not used for this particular purpose before. The socio-demographic aspect was considered along the lines advocated by Cokelez and Peacock (1993) and Graves (2008), who demonstrated the utility of GIS for analysing environmental variables affecting health-care issues.

\section{Material and methods}

\section{Data sources}

The study city was Seoul, the capital of South Korea, with a current population exceeding 10 million according to Statistics Korea of the Korean Statistical Information Service (http://kosis.kr/eng/). Seoul is surrounded by Gyeonggi province, which has a population of approximately 12 million in 2012 according to the same source. General, spatial information was collected from Statistics Korea and its Statistical Geographical Information System (SGIS). The hospital data (from 2010) were collected from the Korean Hospital Association's annual publication (http://www.kha.or.kr/multiLang/en).

To identify the geographical locations of all hospitals

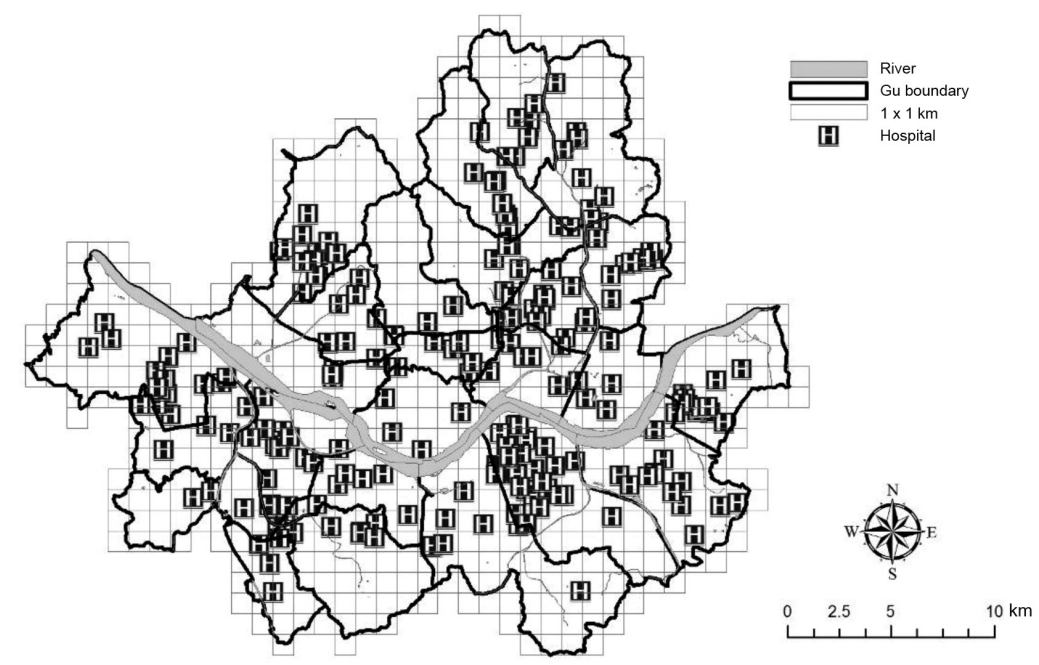

Fig. 1. Locations of hospitals within the study area. 
in Seoul ( $\mathrm{n}=167$ ), their postal addresses for 2010 were entered into a database. A geocoding method was used to convert the address information into spatial data that were subsequently entered into an ArcGIS (ESRI; Redlands, USA) as longitude and latitude. The SGIS provided map data detailing administrative districts, roads and buildings making it possible to identify and calculate various areas and environmental features.

\section{Analytical model}

The SGIS map data were imported into a GIS, and the study area was then divided into 449 cells of uniform $1 \times 1 \mathrm{~km}$ size (Fig. 1). Variables representing each cell were selected and modified from a model used in an earlier study (Lee and Hong, 2010) and incorporated into the framework of this study. Sociodemographic data representing population, economic activity, mobility and housing were identified and collected by the Dong, the smallest administrative district level. One cell sometimes included several Dongs.

Two population indicators, "total population" and "number of people aged >65 years", were included as it was hypothesised that population size and population density are the main issues when planning and forecasting health-care needs, and that people older than 65 years of age have particular needs. Economic activity within the study area was measured using the two variables, "number of businesses" and "number of workers" as previously suggested by Lee and Hong (2010). Mobility was measured by four variables: "number of subway entrances", "road area" $\left(\mathrm{m}^{2}\right)$ and two road types, i.e. "highways and major arterial roads" along with "minor arterials and side roads" since a higher number of subway entrances near a hospital and larger road areas are known to increase accessibility (Lee, 2013). The housing factor was measured using the area in $\mathrm{m}^{2}$ of three building variables: "apartment", "row house" and "detached house". These variables were felt to accurately represent the residential environment in each cell and to test whether residential area influenced the hospital location.

\section{Measurement of the variables}

Different estimation methods were applied to calculate the different types of variables in each cell. Because the parameters "total population", "population aged >65 years", "number of businesses" and "number of workers" in each cell could be measured directly from the map, these variables were estimated using a stepwise procedure. After the population vari- ables per unit area had been calculated for each Dong (by dividing the total population there by the Dong area in $\mathrm{m}^{2}$ ) the intersect function of GIS was applied to calculate the Dong size for each cell (which could include one or multiple Dong(s)). Finally, these two values were multiplied. Since river and road areas differed for each Dong and consequently influenced the final scores in various ways when they were included in the estimation process, the area calculations were adjusted to exclude these areas. Data from the Korea Statistics were used to define these variables.

Road area and residential building area for each cell were calculated by applying the GIS intersect function to each cell. Because these data were stored as polygons, they could be measured directly on the map. The variables "number of subway entrances" and "number of hospitals" in each cell were calculated by summing them. Parameters representing the road areas, house areas and subway entrances were produced using data obtained from the SGIS of Statistics Korea.

The spatial data resulting from the manipulations described above were analysed in three steps. First, their general characteristics were analysed using descriptive and correlation analysis. Second, multivariate linear regression analysis was applied to analyse the relationship between the socio-demographic variables and the number of hospitals. Prior to regression analysis, application of the Kolmogorov-Smirnov test (Khamis, 1990) revealed that the study variables were not normally distributed. The variables were transformed using a natural log function to alleviate skewness (Manning and Mullahy, 2001). Third, geographically weighted regression (GWR) was applied to test the relationship between the study variables and determine if these varied with hospital location.

The ordinary least-squares (OLS) regression model assumes that the relationship between study variables does not vary, and that they provide global relationship estimates. On the other hand, GWR assumes that the relationship varies depending on location. These assumptions were considered in the analytical process. The GWR model produced local regression coefficients, local standard error and local $R^{2}$ values at each geographical location. The Akaike information criterion (AIC) was used to assess whether GWR provided a better fit to the study data than the OLS regression model. The spatial autocorrelation of residual was tested using Moran's $I$ statistic. The $1 \times 1 \mathrm{~km}$ cell was the base analytical unit. Multiple data were managed and analysed using SAS version 9.2 and ArcMap version 10 was used for geocoding hospital addresses and for spatial analysis. 
Table 1. Descriptive statistics for the study variables $(n=449)$.

\begin{tabular}{lrr}
\hline Variable & Average & \multicolumn{1}{c}{ SD* } \\
\hline Number of hospitals & 0.30 & 0.68 \\
Total population & $14,732.21$ & $11,665.81$ \\
Population aged $>65$ years & $1,432.53$ & $1,134.88$ \\
Number of businesses & $9,007.38$ & $9,607.29$ \\
Number of workers & $88,998.87$ & $108,066.02$ \\
Road area & & \\
$\quad$ Highways and arterial roads & $27,384.72$ & $36,918.16$ \\
$\quad$ Minor arterials and side roads & $96,077.83$ & $77,565.02$ \\
Number of subway entrances & & \\
Residential area & 2.17 & 3.85 \\
$\quad$ Apartment area & $19,757.51$ & $22,713.94$ \\
Row house area & $17,033.24$ & $24,022.27$ \\
Detached house area & $52,234.62$ & $66,333.51$ \\
\hline
\end{tabular}

"Standard deviation

\section{Results}

Descriptive statistics of study variables calculated from each cell are presented in Table 1. The average number of hospitals per cell and the standard deviation (SD) was 0.30 and 0.68 , respectively. The estimated average numbers of of "total population", "population aged $>65$ years", "businesses" and "workers" in each cell were $14,732.21,1,432.53,9,007.38$ and $88,998.87$, respectively. The average area of minor arterial roads and side roads was three times larger than that of highways and major arterial roads. For housing, the total area of detached houses was the largest, followed by apartments and row houses - in that order.
Table 2 presents the correlation coefficients (CFs) of the study variables. The variables, "population aged $>65$ years", "number of businesses" and "number of workers", correlated strongly with the "total population" one $(\mathrm{CF}>0.8)$. The variable "row house area" also had a CF above 0.8 with respect to "detached house area." These high CFs indicate possible multicollinearity problems amongst the variables. For this reason, four of them, "population aged $>65$ ", "number of businesses", "number of workers" and "detached house area", were not included in subsequent multivariate analysis.

The results of the OLS multiple linear regression analyses for the number of hospitals in each cell are presented in Table 3. Three variables ("highway and major arterial roads", "number of subway entrances" and "row house area") had statiscally significant correlations to the number of hospitals per cell $(\mathrm{P}<0.05)$, and all three variables had positive regression coefficients: $0.01,0.10$ and 0.02 , respectively. The "number of subway entrances" factor produced the largest regression coefficient. The variance inflation factor (VIF) scores were not high indicating that multicollinearity did not influence this model.

Moran's I was calculated to test the spatial autocorrelation of regression residuals to determine if they were randomly spatially distributed. When this index is significant, geographical features (cells) are spatially autocorrelated meaning that cells near each other tend to be more similar than they are when compared to those farther away. The Moran's I of the model used here $(0.042, \mathrm{P}=0.114)$ indicates that the autocorrelation of the spatial features was low.

Table 2. Pearson's correlation coefficients for the study variables.

\begin{tabular}{|c|c|c|c|c|c|c|c|c|c|c|c|}
\hline & $\mathrm{A}$ & B & $\mathrm{C}$ & $\mathrm{D}$ & $\mathrm{E}$ & F & G & $\mathrm{H}$ & I & $\mathrm{J}$ & $\mathrm{K}$ \\
\hline A & 1.00 & - & - & - & - & - & - & - & - & - & - \\
\hline B & 0.31 & 1.00 & - & - & - & - & - & - & - & - & - \\
\hline C & 0.30 & 0.99 & 1.00 & - & - & - & - & - & - & - & - \\
\hline $\mathrm{D}$ & 0.30 & 0.90 & 0.90 & 1.00 & - & - & - & - & - & - & - \\
\hline $\mathrm{E}$ & 0.29 & 0.86 & 0.86 & 0.99 & 1.00 & - & - & - & - & - & - \\
\hline $\mathrm{F}$ & 0.18 & 0.06 & 0.05 & 0.27 & 0.31 & 1.00 & - & - & - & - & - \\
\hline G & 0.31 & 0.70 & 0.72 & 0.68 & 0.64 & 0.19 & 1.00 & - & - & - & - \\
\hline $\mathrm{H}$ & 0.36 & 0.38 & 0.39 & 0.46 & 0.46 & 0.25 & 0.43 & 1.00 & - & - & - \\
\hline I & 0.33 & 0.71 & 0.69 & 0.68 & 0.66 & 0.17 & 0.72 & 0.46 & 1.00 & - & - \\
\hline $\mathrm{J}$ & 0.36 & 0.66 & 0.67 & 0.62 & 0.59 & 0.09 & 0.67 & 0.36 & 0.77 & 1.00 & - \\
\hline $\mathrm{K}$ & 0.36 & 0.66 & 0.68 & 0.67 & 0.64 & 0.13 & 0.68 & 0.38 & 0.71 & 0.85 & 1.00 \\
\hline
\end{tabular}

$\mathrm{A}=$ number of hospitals; $\mathrm{B}=$ total population; $\mathrm{C}=$ population over 65 years; $\mathrm{D}=$ number of businesses; $\mathrm{E}=$ number of workers; $\mathrm{F}=$ area of highways and major arterial roads; $\mathrm{G}=$ area of minor arterial road and side roads; $\mathrm{H}=$ number of subway entrances; $\mathrm{I}=$ apartment area; $\mathrm{J}=$ row house area; $\mathrm{K}=$ detached house area.

$\mathrm{P}<0.05$ for all measured variables. 
Table 3. Results of multiple linear ordinary least-squares (OLS) regression.

\begin{tabular}{lcc}
\hline Independent variable & Estimate & $\mathrm{VIF}^{\mathrm{a}}$ \\
\hline Total population & 0.02 & 2.51 \\
Highways and major arterial roads & $0.01 *$ & 1.23 \\
Minor arterial road and side roads & -0.01 & 2.66 \\
Number of subway entrances & $0.10 *$ & 1.32 \\
Apartment area & 0.00 & 3.47 \\
Row house area & $0.02 *$ & 2.68 \\
Goodness of fit & Adj. $\mathrm{R}^{2}=0.199, \mathrm{P}<0.001, \mathrm{AIC}^{\mathrm{b}}=435.73$ \\
Spatial autocorrelation & Moran's $I=0.042, \mathrm{P}=0.114$ & \\
\hline
\end{tabular}

${ }^{\mathrm{a}}$ Variance inflation factor; ${ }^{\mathrm{b}}$ Akaike's information criterion; * $\mathrm{P}<0.01$.

Dependent variable: "number of hospitals".

Results from the GWR model are presented in Table 4. There were no large differences between coefficients of the study variables across the cells. Maximum coefficients were similar to minimum coefficients in six independent variables. In addition, minimum local $R^{2}$ was similar to the maximum local $R^{2}$. Adjusted $R^{2}$ and AIC of the GWR model did not change relative to those of the OLS model. Goodness of fit scores did not change, indicating that it was not influenced in GWR. The GWR model did not improve model fit indices when compared to the OLS regression, which explained overall data relationships within the study city.

Fig. 2 maps the distribution for the standardised residual (Map A) and local $R^{2}$ (Map B). No discernible standardised residual pattern was observed, and the local $R^{2}$ was slightly higher in the eastern section of Seoul when compared to the western part. However, there were no notable score differences.

\section{Discussion}

Analysis based on GIS not only provides useful information for hospital managers about the effectiveness of current hospital locations, but also points to the usefulness of analytical models when assessing future hospital locations. Integrating multiple data sets within a GIS can identify optimal locations that will fulfil planning objectives. Kassaye and Tseng (1990) proposed that hospitals respond more to micro-environmental changes than macro-environmental ones. The small areal unit used in this study may not only have helped to identify environmental characteristics in detail, but could also have enhanced comparability among the cells. No differences were observed in performance statistics between the OLS and GWR (the AIC scores did not change) indicating that when hospital locations were analysed based on $1 \times 1 \mathrm{~km}$ cells,

Table 4. Results of the geographically weighted regression (GWR) model.

\begin{tabular}{|c|c|c|c|c|}
\hline Variable & Average & $\mathrm{SD}^{\mathrm{a}}$ & Min & Max \\
\hline Total population & 0.01970 & 0.00001 & 0.01969 & 0.01972 \\
\hline Highways and major arterial roads & 0.00734 & $<0.00001$ & 0.00733 & 0.00734 \\
\hline Minor arterial road and side roads & -0.00739 & $<0.00001$ & -0.00739 & -0.00739 \\
\hline Number of subway entrances & 0.09676 & 0.00001 & 0.09674 & 0.09679 \\
\hline Apartment area & -0.00263 & $<0.00001$ & -0.00264 & -0.00263 \\
\hline Row house area & 0.02107 & 0.00001 & 0.02105 & 0.02108 \\
\hline Local $\mathrm{R}^{2}$ & 0.2056 & 0.00001 & 0.20562 & 0.20566 \\
\hline Bandwidth & \multicolumn{2}{|c|}{$490,370.72$} & & \\
\hline Goodness of fit & \multicolumn{2}{|c|}{ Adj. $\mathrm{R}^{2}=0.199, \mathrm{AIC}^{\mathrm{b}}=435.730$} & & \\
\hline Spatial autocorrelation & \multicolumn{2}{|c|}{ Moran's $I=0.042, \mathrm{P}=0.114$} & & \\
\hline
\end{tabular}

a Standard deviation; 'Akaike's information criterion.

Dependent variable: "number of hospitals". 

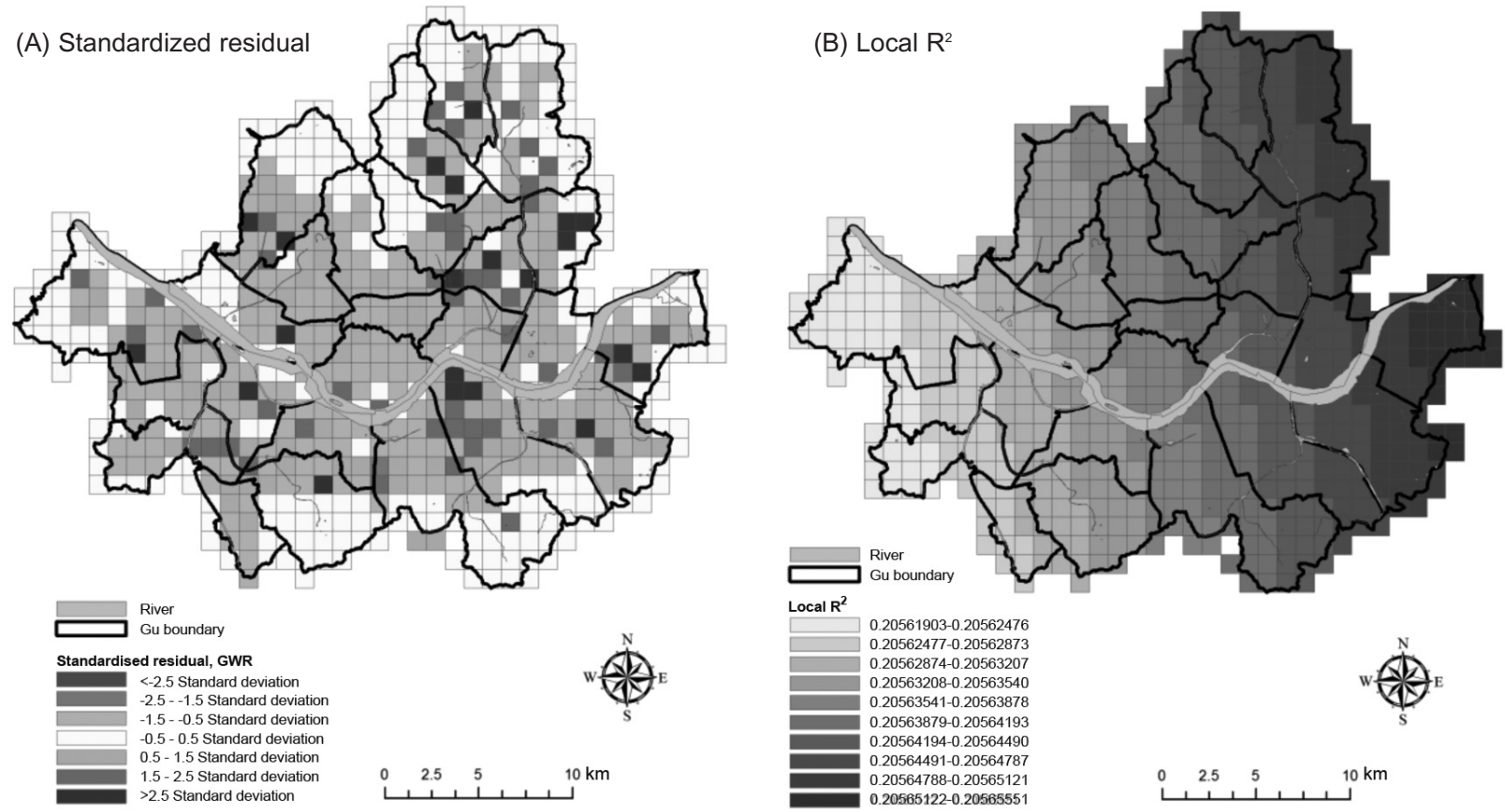

Fig. 2. Standardised residual and local $\mathrm{R}^{2}$ in the geographically weighted regression (GWR) model.

spatial autocorrelation is not an issue when using the OLS model. The grid method enabled examination of the regions surrounding hospitals identifying and analysing comparable units, but results may have been influenced by limiting the cell size to $1 \times 1 \mathrm{~km}$. In addition, the values of socio-demographic variables can change depending on the cell size thereby influencing and regression coefficients.

\section{Population}

Graves (2008) and Hall et al. (1986) note that the location of health-care centres and population are important, inter-related factors in the analysis of health aspects in society. Both studies consider proximity for the greatest number of people to be the decisive factor. Comber et al. (2011) analysed the influence of spatial accessibility on the utilization of care services and found that it could enhance the utility of services, while Graham (1984) argues that planners need to consider an array of demographic variables and hypothesizes that population size and density are main issues when planning and forecasting business needs. Knowing the population characteristics was therefore considered to be important for providing products that fit the market.

Population density intuitively attracts hospital location, and as it was thought that the elderly would be an even stronger factor, two population variables were included in the study. However, since the "population aged $>65$ years" variable showed a high correlation with the "total population" one (along with number of businesses and workers), none of these variables were analysed further due to the strong risk for multicollinearity.

\section{Economic activity}

When a health-care organisation tasked with providing services to the local population, the combination of income data and environmental data can assist in identifying the most appropriate locations to service that population (Lee and Hong, 2010). Following this general idea, proxies for neighbourhood economic activity ("number of businesses" and "number of workers") were included. However, in the end both these variables had to be excluded because of the same high correlation coefficients mentioned above with respect to the population. For this reason, the potential influence of regional economy and economic status of neighbourhoods on the location of hospitals cannot be commented on here.

\section{Mobility}

The geographical accessibility of hospitals is an important issue affecting the use of hospital services (Love and Lindquist, 1995; Lee, 2013). Traffic convenience has been considered in decisions about the location of dialysis facilities (Eben-Chaime and 
Pliskin, 1992) and Graham (1984) considers labour force and its mobility important factors in planning activities. In this study, mobility was measured by road area, road type and the number of subway entrances. Seoul has a well-developed subway network and, naturally, a high number of subway entrances as well as a large road area near a hospital increase accessibility and ease of reaching that facility. The papers by Boscarino and Steiber (1982) and Vahidnia et al. (2009) both argue that convenient road access is a major factor determining hospital location. "Highway and major arterial roads" and "number of subway entrances" used in this study are proxy variables representing population flux and traffic convenience for reaching hospitals. Information from the Korean Statistical Information Service indicates that the subway system in Seoul carried approximately 2.359 billion passengers in 2011. This high passenger volume may thus have influenced the selection of hospital location.

Many Koreans will not make appointments when visiting outpatient hospital departments (except in the case of major (tertiary) hospitals). Most hospitals in Korea are private and less than $10 \%$ of all hospital beds are provided by public hospitals. There is a competitive advantage in locating hospitals where the road network is good or near subway entrances, thereby gaining better public exposure and improved public awareness.

\section{Housing}

The residential factor was measured using three building variables: "apartments", "row houses" and "detached houses". These variables were included to accurately represent the residential environment in each cell and to test whether residential area influenced the locations of hospitals. Vahidnia et al. (2009) argued that the proximity of a clinic to residences was assumed to increase resident awareness of and accessibility to the facility. Hindle and Ngwube (1990) studied the utility of regionally supplied specialist services and found that the proximity of patients to specialist services influenced service utility. For housing, the "detached house area" variable had to be deleted due to the risk for multicollinearity. Of the potential influence of "apartment area" and "row house", the latter seems to more important. The finding that the "row house area" estimate (0.02) was greater than that of "highway and major arterial roads" (estimate $=0.01$ ) suggests that the residential environment can also be used as a factor in planning hospital distribution.
However, the height of the building was not considered when measuring apartment area and the possibility exists that the regression results might change when height information is considered.

\section{Limitations}

The generalisation of the results delivered by study is limited since it only considers hospitals from one metropolitan city, and therefore only a portion of the Korean hospital industry is represented. In addition, cell size and economic activity can potentially influence study results as discussed above, but need to be studied in more detail.

Information about spatial features relevant to hospital location is provided; however, how location is related to hospital performance, e.g. comparing variables to the number of outpatients in relation to inpatients, was not investigated. Geographical convenience is considered as one major factor in determining the use of medical services (Newton and Goldacre, 1994). For example, variables that can improve convenience with respect to traffic should be significant in explaining hospital distribution. Further study is needed to test whether hospitals located near superior traffic systems, also influence their performance.

\section{Conclusions}

Mobility and accessibility appeared to be decisive when people seek health care. Three factors (highway and major arterial roads along with the number of subway entrances and row houses) were statistically significant in explaining the variance of hospital distribution for each cell. The overall results show that GIS is a useful tool for analysing and understanding location strategies, an approach that should be useful for decision-makers concerned with the distribution of hospitals and other health care centres in a city.

The hospital industry is highly competitive in urban areas. Understanding preferences for hospital location can contribute to better strategic decision-making and improve competitive advantage. Further research is needed to determine missing details regarding how location is related to the overall hospital performance.

\section{References}

Alcaraz KI, Kreuter MW, Bryan RP, 2009. Use of GIS to identify optimal settings for cancer prevention and control in African American communities. Prev Med 49, 54-57.

Boscarino J, Steiber SR, 1982. Hospital shopping and consumer 
choice. J Health Care Mark 2, 15-23.

Cokelez S, Peacock E, 1993. A modeling approach to hospital location for effective marketing. J Hosp Mark 8, 29-40.

Comber AJ, Brunsdon C, Radburn R, 2011. A spatial analysis of variations in health access: linking geography, socio-economic status and access perceptions. Int J Health Geogr 10, 44.

Eben-Chaime M, Pliskin JS, 1992. Incorporating patient travel times in decisions about size and location of dialysis facilities. Med Decis Making 12, 44-51.

Graham RJ, 1984. Population issues in economic planning: uses of demography in business. J Aust Popul Assoc 1, 82-88.

Graves BA, 2008. Integrative literature review: a review of literature related to geographical information systems, healthcare access, and health outcomes. Perspect Health Inf Manag 5, 11.

Hall O, Bloemer H, Cantrell B, Orebaugh M, 1986. Using social indicators to locate mental health facilities. J Ment Health Adm 13, 51-57.

Hindle T, Ngwube C, 1990. The relative accessibility for health districts to regionally supplied specialist services. Health Serv Manage Res 31, 16-21.

Jones PK, Jones SL, Yoder L, 1982. Hospital location as a determinant of emergency room utilization patterns. Public Health Rep 97, 445-451.

Kassaye WW, Tseng KC, 1990. Effects of changes in micro- and macro-environmental factors on the supply of hospitals services. J Hosp Mark 41, 23-33.

Khamis HJ, 1990. The delta-corrected Kolmogorov Smirnov test for goodness of fit. J Stat Plan Inference, 24, 317-335.

Lee JE, Sung JH, Ward WB, Fos PJ, Lee WJ, Kim JC, 2007. Utilization of the emergency room: impact of geographic distance. Geospat Health 1, 243-253.

Lee KS, 2013. Disparity in the spatial distribution of clinics within a metropolitan city. Geospat Health 7, 199-207.

Lee KS, Hong SJ, 2010. A study on the relationship between the locational characteristics of oriental medicine hospitals and the number of patients. Korean J Health Policy Adm 20, 97-113.

Love D, Lindquist P, 1995. The geographical accessibility of hospitals to the aged: a geographic information systems analysis within Illinois. Health Serv Res 29, 629-651.

Manning WG, Mullahy J, 2001. Estimating log models: to transform or not to transform? J Health Econ 20, 461-494.
Messina JP, Shortridge AM, Groop RE, Varnakovida P, Finn MJ, 2006. Evaluating Michigan's community hospital access: spatial methods for decision support. Int J Health Geogr 5, 42. Mitropoulos P, Mitropoulos I, Giannikos I, Sissouras A, 2006. A biobjective model for the locational planning of hospitals and health centers. Health Care Manag Sci 92, 171-179.

Murad AA, 2008. Defining health catchment areas in Jeddah city, Saudi Arabia: an example demonstrating the utility of geographical information systems. Geospat Health 2, 151-160.

Newton J, Goldacre M, 1994. How many patients are admitted in districts other than their own, and why? J Public Health Med 162, 159-164.

Passalent L, Borsy E, Landry MD, Cott C, 2013. Geographic information systems GIS: an emerging method to assess demand and provision for rehabilitation services. Disabil Rehabil 35, 1-10.

Peled R, Reuveni H, Pliskin JS, Benenson I, Hatna E, Tal A, 2006. Defining localities of inadequate treatment for childhood asthma: a GIS approach. Int J Health Geogr 5, 3.

Rosero-Bixby L, 2004. Spatial access to health care in Costa Rica and its equity: a GIS-based study. Soc Sci Med 58, 12711284.

Schuurman N, Leight M, Berube M, 2008. A Web-based graphical user interface for evidence-based decision making for health care allocations in rural areas. Int J Health Geogr 7, 49. Tanser F, 2006. Methodology for optimising location of new primary health care facilities in rural communities: a case study in KwaZulu-Natal, South Africa. J Epidemiol Community Health 60, 846-850.

Vahidnia MH, Alesheikh AA, Alimohammadi A, 2009. Hospital site selection using fuzzy AHP and its derivatives. J Environ Manage 90, 3048-3056.

Walsh SJ, Page PH, Gesler WM, 1997. Normative models and healthcare planning: network-based simulations within a geographic information system environment. Health Serv Res 32, 243-260.

Wilson P, Tedeschi P, 1984. Community correlates of hospital use. Health Serv Res 19, 333-355.

Wong NS, Lee SS, Lin H, 2010. Assessing the spatial distribution of methadone clinic clients and their access to treatment. Harm Reduct J 7, 14. 